\title{
C-terminal residues of skeletal muscle calsequestrin are essential for calcium binding and for skeletal ryanodine receptor inhibition
}

Nicole A Beard ${ }^{1,2^{*}}$ and Angela F Dulhunty ${ }^{1}$

\begin{abstract}
Background: Skeletal muscle function depends on calcium signaling proteins in the sarcoplasmic reticulum (SR), including the calcium-binding protein calsequestrin (CSQ), the ryanodine receptor (RyR) calcium release channel, and skeletal triadin $95 \mathrm{kDa}$ (trisk95) and junctin, proteins that bind to calsequestrin type 1 (CSQ1) and ryanodine receptor type 1 (RyR1). CSQ1 inhibits RyR1 and communicates store calcium load to RyR1 channels via trisk95 and/or junctin.
\end{abstract}

Methods: In this manuscript, we test predictions that CSQ1's acidic C-terminus contains binding sites for trisk95 and junctin, the major calcium binding domain, and that it determines CSQ1's ability to regulate RyR1 activity.

Results: Progressive alanine substitution of C-terminal acidic residues of CSQ1 caused a parallel reduction in the calcium binding capacity but did not significantly alter CSQ1's association with trisk95/junctin or influence its inhibition of RyR1 activity. Deletion of the final seven residues in the C-terminus significantly hampered calcium binding, significantly reduced CSQ's association with trisk95/junctin and decreased its inhibition of RyR1. Deletion of the full C-terminus further reduced calcium binding to CSQ1 altered its association with trisk95 and junctin and abolished its inhibition of RyR1.

Conclusions: The correlation between the number of residues mutated/deleted and binding of calcium, trisk95, and junctin suggests that binding of each depends on diffuse ionic interactions with several C-terminal residues and that these interactions may be required for CSQ1 to maintain normal muscle function.

Keywords: Calsequestrin, Sarcoplasmic reticulum, Ryanodine receptor, $\mathrm{Ca}^{2+}$ binding protein, Skeletal muscle

\section{Background}

In skeletal muscle, the rapid and co-ordinated release of calcium ions from the internal sarcoplasmic reticulum (SR) store is essential in triggering muscle contraction. Skeletal muscle activation, in response to an action potential on the surface membrane, activates voltagegated L-type $\mathrm{Ca}^{2+}$ channels which, in turn, initiate SR $\mathrm{Ca}^{2+}$ release. The $\mathrm{SR} \mathrm{Ca}^{2+}$ release channel is the ligandgated ryanodine receptor (RyR), a large $(>2 \mathrm{mDa})$ homotetrameric ion channel, which releases between $10 \%$ to $17 \%$ of the total $\mathrm{SR} \mathrm{Ca}^{2+}$ with each action potential

\footnotetext{
* Correspondence: nicole.beard@canberra.edu.au

'John Curtin School of Medical Research, Australian National University, Garran Road, Canberra ACT 2601, Australia

${ }^{2}$ Discipline of Biomedical Sciences, Centre for Research in Therapeutic Solutions, Faculty of Education Science, Technology and Maths, University of Canberra, Kirinari Street, Bruce ACT 2601, Australia
}

(reviewed in [1]). Ryanodine receptor type 1 (RyR1) is central to excitation-contraction coupling, and its activity and ability to release $\mathrm{Ca}^{2+}$ is refined by the level of $\mathrm{Ca}^{2+}$ load inside the SR and by a luminal SR protein complex, including calsequestrin (CSQ), skeletal triadin $95 \mathrm{kDa}$ (trisk95), and junctin.

CSQ is the most abundant $\mathrm{Ca}^{2+}$ buffering protein found within the SR, with its concentration reported to be between 11 and $36 \mu \mathrm{mol}$ (l fiber volume) ${ }^{-1}$, dependent on muscle type [2]. Calsequestrin type 1 (CSQ1) is the only isoform expressed in fast twitch muscle fibers, while equal amounts of CSQ1 and the so-called cardiac CSQ2 isoform are expressed in slow twitch fibers [2]. Both isoforms display a high degree of homology, with the C-terminal tail extended in CSQ2. CSQ1 is a low affinity, moderate to high-capacity $\mathrm{Ca}^{2+}$-binding protein, binding between 
50 and $80 \mathrm{~mol} \mathrm{Ca}^{2+} /$ mole CSQ1 with a $K_{\mathrm{D}}$ of approximately 1 to $2 \mathrm{mM}[3,4]$. CSQ1 buffers free SR $\mathrm{Ca}^{2+}$ to approximately $1 \mathrm{mM}$ during the contraction/relaxation cycle.

Research over the past 2 decades has shown that CSQ1 plays additional roles in global regulation of $\mathrm{Ca}^{2+}$ signaling in skeletal and cardiac muscles. A retrograde signal from CSQ1 is thought to be important for store-operated $\mathrm{Ca}^{2+}$ entry in skeletal muscle [5]. CSQ1 inhibits RyR1, while in the heart, CSQ2 activates the cardiac RyR [6]. CSQ is considered to be a luminal $\mathrm{Ca}^{2+}$ sensor for the RyR, communicating $\mathrm{Ca}^{2+}$ store load to the channel [7-9]. In skeletal muscle, CSQ1 acts as a break on the channel, to curtail SR $\mathrm{Ca}^{2+}$ release under conditions of lower store load and is essential for normal muscle function. Knockout of CSQ1 leads to a malignant hyperthermia phenotype with excess $\mathrm{Ca}^{2+}$ release under stress [10]. Despite the functional interaction between CSQ1 and RyR1, there is no evidence that they bind directly in vivo. Instead, both proteins bind to junctin and trisk95 [11-16], forming a luminal protein complex, which allows CSQ1-RyR1 communication. The importance of the luminal protein complex in modulating RyR activity and excitation-contraction coupling is highlighted by the fact that mutation or alteration in expression of these proteins results in severe contractile dysfunction [17-23].

At in vivo luminal $\left[\mathrm{Ca}^{2+}\right] \mathrm{s}$, CSQ1 monomers selfassociate to form polymers, which are observed as long linear strand-like structures closely associated with the junctional face membrane in electron micrographs [24]. The dynamic polymerization of CSQ1 is highly dependent on $\mathrm{Ca}^{2+}$. At low $\left[\mathrm{Ca}^{2+}\right]$ of $100 \mathrm{nM}$, CSQ1 exists in an unfolded randomly coiled structure [25]. As $\left[\mathrm{Ca}^{2+}\right]$ is increased toward $100 \mu \mathrm{M}, \mathrm{CSQ} 1$ undergoes a conformational change [25-27] and increases in helicity $[26,28]$. The conformational changes include the folding of the three thioredoxin domains within CSQ1 and the subsequent formation of front-to-front dimers between two folded monomers [27]. In this process, the $\mathrm{N}$ terminus from one monomer inserts into a groove between two $\beta$-strands of domain II of the second monomer [27]. A secondary intermolecular interaction among front-to-front dimers allows them to associate in a backto-back configuration, bringing together two electronegative surfaces to form linear polymers [27].

Several factors influence CSQ1's moderate to high $\mathrm{Ca}^{2+}$ binding capacity. $\mathrm{Ca}^{2+}$ binding capacity is partially determined by overall net charge [29]; however, the calculated net charge of skeletal CSQ1 is insufficient for the amount of $\mathrm{Ca}^{2+}$ that it can bind in its polymer form [30]. This suggests that additional sites for $\mathrm{Ca}^{2+}$ binding must be formed as CSQ1 polymerizes. The roles of the acidic-rich C-terminal tail (residues 354 to 367 in rabbit) has been postulated to play an important role in inferring the $\mathrm{Ca}^{2+}$ binding capacity of CSQ1 $[15,29,31]$, although the mechanisms have not been well understood. Recent molecular dynamic modeling studies postulate that $\mathrm{Ca}^{2+}$ binding sites within the C-terminus of CSQ1 serve to neutralize the interface and enable CSQ polymerization and subsequent high-capacity $\mathrm{Ca}^{2+}$ binding [32]. Furthermore, the existence of low-affinity $\mathrm{Ca}^{2+}$ binding sites on CSQ1 may serve, at least in part, to induce additional $\mathrm{Ca}^{2+}$ binding sites [32], allowing for CSQ's high-capacity $\mathrm{Ca}^{2+}$ binding. That the C-terminal tail is essential for binding capacity is supported experimentally, as its deletion in CSQ2 severely reduces $\mathrm{Ca}^{2+}$ binding capacity [29]. The Cterminal tail contains the highest surface negative charge density [30] and was initially thought to be responsible for at least $26 \%$ of the $\mathrm{Ca}^{2+}$ binding, although simulations suggest this to be as low as 10\% [32].

CSQ1's acidic-rich C-terminal tail also constitutes a "hot spot" for CSQ1 protein associations. CSQ1 residues 354 to 367 contain the binding site for trisk 95 and have been suggested to contain critical residues that support its interaction with junctin [15]. We are yet to understand the true nature of this region, because the anatomical details of the acidic C-terminal tail are not resolved in published crystal structures of CSQ1 (reviewed in [33]) and because there is little information on the role of specific residues within the $\mathrm{C}$ terminal tail in the various functions of CSQ1.

In this paper, we have dissected the functional importance of residues within CSQ1's C-terminal tail. We have examined the effects of substitutions or deletions within the C-terminal tail on CSQ1's $\mathrm{Ca}^{2+}$ binding capacity, its ability to associate with trisk 95 and junctin and its ability to regulate RyR1 channel activity to ensure normal muscle function.

\section{Methods \\ Materials}

The monoclonal 34C anti-RyR1 antibody, monoclonal VIIID12 anti-CSQ1 antibody, and rabbit affinityisolated polyclonal anti-CSQ antibody (ab 3516) were from Abcam (Cambridge, MA, USA). Polyclonal antijunctin was a generous gift from Dr. Steven Cala (Wayne State University, MI, USA). Phospholipids were from Avanti Polar Lipids (Alabaster, AL, USA). The Pierce IP kit was from ThermoFisher Scientific (Scoresby, Vic, Australia), ${ }^{45} \mathrm{Ca}^{2+}$ was from PerkinElmer (Glen Waverley, VIC, Australia), and Glutathione Sepharose 4B was from GE Healthcare (Rydalmere, NSW, Australia). The Bio-Rad DC protein determination assay and sodium dodecyl sulphate-polyacrylamide gel electrophoresis (SDS-PAGE)/Western blot apparatus and consumables were from Bio-Rad (Gladesville, NSW, Australia), and the multi-mutagenesis kit was from 
Stratagene (now Agilent Technologies Inc, Mulgrave, VIC, Australia). Microcon centrifugal filter concentrators were from Millipore (Bayswater, VIC, Australia). The monoclonal anti-triadin antibody (IIG12) and all other chemicals were obtained from Sigma-Aldrich (Castle Hill, NSW, Australia).

\section{Ethics approval}

All animal work was approved by the Australian National University and University of Canberra Animal Ethics Committees.

\section{CSQ1 mutation, expression, and purification}

To probe the functional importance of the acidic-rich C-terminal tail in CSQ1, wild-type (WT) CSQ1 and several alanine substitution and deletion mutants (see Figure 1) were generated by PCR of rabbit CSQ1 cDNA using the Stratagene multi-mutagenesis kit. All CSQ1 constructs were subcloned into a pGEX5x1 vector, containing a $\mathrm{N}$-terminal glutathione S-transferase (GST) tag and expressed as previously described [34]. The expressed CSQ1 proteins were dialyzed against $20 \mathrm{mM}$ MOPS, $150 \mathrm{mM} \mathrm{NaCl}$, and $1 \mathrm{mM} \mathrm{CaCl} 2$ (pH 7.4). Where necessary, the protein underwent secondary purification using anti-CSQ1 immunoprecipitation (Pierce crosslinking IP kit), following manufacturer's instruction.

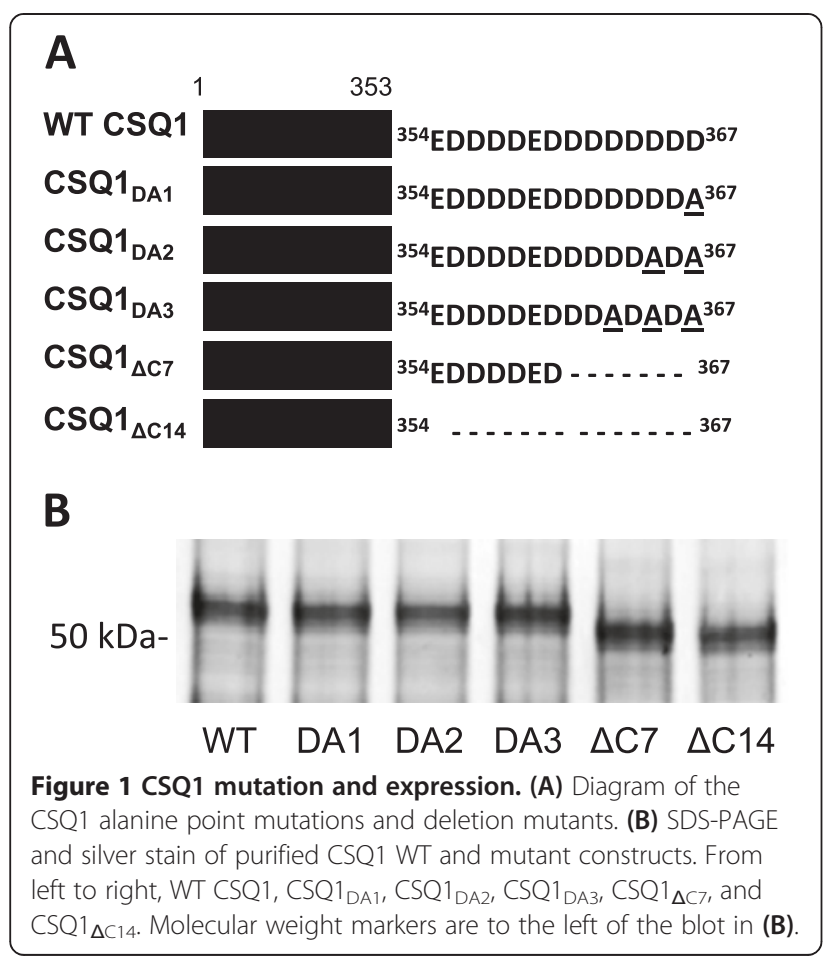

\section{SR vesicle preparation}

SR vesicles from back and leg muscles from New Zealand White Rabbits were prepared as described in [7,9,35].

RyR1 purification from skeletal SR vesicles was performed as described in [36]. The purified RyR1 was concentrated, snap-frozen, and stored at $-70^{\circ} \mathrm{C}$. The protein was run on SDS polyacrylamide gels, and immunoblots probed with anti-RyR1, anti-CSQ1, anti-triadin and antijunctin antibodies to detect contamination by these proteins.

SDS-PAGE and Western blot were performed according to $[37,38]$. Briefly, proteins were separated on $4 \%$ to $15 \%$ or $4 \%$ to $20 \%$ SDS polyacrylamide gels and transferred to polyvinylidene difluoride (PVDF) membrane for Western blot. PVDF membranes were exposed to primary antibodies to CSQ1, junctin, trisk95, and RyR1 (as appropriate) and secondary HRP-conjugated antibody, prior to chemiluminsence detection. Images were developed using a Kodak OXmat M20 film processor onto Kodak Hyper ECL film.

\section{Purification of trisk95 and junctin from skeletal SR vesicles}

Trisk 95 and junctin were isolated by SDS preparative gel electrophoresis, as previously described [39].

\section{$\mathrm{Ca}^{2+}$ binding capacity}

The $\mathrm{Ca}^{2+}$ binding capacities of CSQ1 constructs were determined using a modified ${ }^{45} \mathrm{Ca}^{2+}$ spin dialysis binding assay [14]. In brief, $200 \mu \mathrm{g}$ of CSQ1 constructs were conjugated with ${ }^{45} \mathrm{Ca}^{2+}$ by incubation in $150 \mathrm{mM} \mathrm{NaCl}$, $20 \mathrm{mM}$ MOPS, $100 \mu \mathrm{M}$ to $5 \mathrm{mM} \mathrm{CaCl}_{2}$ (pH 7.4), and $2.6 \mathrm{kBq}{ }^{45} \mathrm{Ca}^{2+}$ for $15 \mathrm{~min}$ at room temperature. Unconjugated ${ }^{45} \mathrm{Ca}^{2+}$ was removed by centrifugation of the samples in a Microcon centrifugal filter concentrator at $12,000 \times g$ for $10 \mathrm{~min} .{ }^{45} \mathrm{Ca}^{2+}$ radioactivity of the retentate (containing CSQ $1-{ }^{45} \mathrm{Ca}^{2+}$ ) and of an unfiltered sample aliquot were counted using a Packard 1500 TriCarb liquid scintillation analyzer (Packard Instrument Co., Downers Grove, IL, USA). Protein concentration of the retentate (containing CSQ $1-{ }^{45} \mathrm{Ca}^{2+}$ ) was determined using a Bio-Rad DC protein determination assay, according to manufacturer's instruction. Data is presented as nmol ${ }^{45} \mathrm{Ca}^{2+} / \mathrm{mg}$ CSQ1.

\section{Co-immunoprecipitation}

In vitro binding of CSQ1 to purified trisk95 and junctin was performed using a Pierce co-immunoprecipitation kit as per manufacturer's instruction, with the following changes. Co-immunoprecipitation was performed in a buffer containing $20 \mathrm{mM}$ MOPS, $150 \mathrm{mM} \mathrm{NaCl}$, and 1 $\mathrm{mM} \mathrm{CaCl}_{2}$ (pH 7.4), using a 2:1 protein ratio (weight) of CSQ1 to either junctin, trisk95, or RyR1. 


\section{Affinity chromotography}

CSQ1-RyR1 interactions were investigated using affinity chromatography as previously described [34].

\section{Turbidity measurements}

Solution turbidity [40,41] was monitored spectrophotometrically in a $1-\mathrm{cm}$ path length quartz cuvette. Three micromolar protein was suspended in a buffer containing $20 \mathrm{mM}$ Tris and $100 \mathrm{mM} \mathrm{KCl} \mathrm{pH} \mathrm{7.4.} \mathrm{Small} \mathrm{aliquots}$ of $\mathrm{CaCl}_{2}$ were added to the cuvette to final concentrations of 0.1 to $3 \mathrm{mM}$. After each addition, the cuvette was stirred and allowed to equilibrate at room temperature for $7.5 \mathrm{~min}$, after which the absorbance was recorded at $350 \mathrm{~nm}$. Absorbance values were corrected for any change in absorbance due to buffer alone. Turbidity is a measure of CSQ1 transition from soluble to insoluble forms as a function of $\left[\mathrm{Ca}^{2+}\right]$, and increased absorbance at $350 \mathrm{~nm}$ reflects the shift toward insoluble particles.

\section{Single channels}

Artificial planar bilayers separating two baths (cis and trans) were formed as described previously [7,34]. Native SR vesicles $(50 \mu \mathrm{g})$ or purified RyR1 $(10 \mu \mathrm{g})$ were added to the cis solution so that the cytoplasmic surface of the SR and RyR1 faced this solution after incorporation. Solution constituents were as follows: cis $230 \mathrm{mM}$ CsMS, $20 \mathrm{mM} \mathrm{CsCl}, 1 \mathrm{mM} \mathrm{CaCl}_{2}$, and $10 \mathrm{mM}$ TES (pH 7.4) and trans - $30 \mathrm{mM} \mathrm{CsMS,} 20 \mathrm{mM} \mathrm{CsCl}$, $1 \mathrm{mM} \mathrm{CaCl}_{2}$, and $10 \mathrm{mM}$ TES (pH 7.4). Free $\left[\mathrm{Ca}^{2+}\right]$ in all solutions was verified using a $\mathrm{Ca}^{2+}$ electrode. Single channel parameters were measured using the channel 2 program (developed by P.W. Gage and M. Smith, John Curtin School of Medical Research, Canberra, Australia). Single channel recordings were obtained at +40 and $-40 \mathrm{mV}$, at $23 \pm 2^{\circ} \mathrm{C}$. Channel activity was assessed from $90 \mathrm{~s}$ of recording at each potential, by directly measuring open probability $\left(P_{o}\right)$, mean open time $\left(T_{o}\right)$, mean closed time $\left(T_{c}\right)$, and open frequency $\left(F_{o}\right)$ in single channel recordings using threshold discrimination or indirectly from the fractional mean current $\left(I_{F}\right)$ when more than one channel was opening [9]. For simplicity, $P_{o}$ and $P_{F}$ are combined in calculations of average $P_{o}$ or relative $P_{o}[9]$.

\section{Statistics}

Average data are presented as mean \pm SE. The significance of differences between control and test values was tested using a Student's $t$-test for paired data. In some cases, to reduce the effects of variability in control parameters $\left(P_{o \text { Con }}, T_{o \text { Con }}, T_{c \text { Con }}\right.$, and $\left.F_{o \text { Con }}\right)$ and to evaluate parameters after CSQ1 construct addition $\left(P_{o \mathrm{CSQ}}, T_{o \mathrm{CSQ}}, T_{c \mathrm{CSQ}}\right.$, and $\left.F_{o \mathrm{CSQ}}\right)$, data were expressed as the difference between $\log _{10} X_{\mathrm{CSQ}}$ and $\log _{10} X_{\mathrm{Con}}$ for each channel (for example, $\left.\log P_{o \mathrm{CSQ}}-\log P_{o \mathrm{Con}}\right)$. The difference from control was assessed with a paired $t$-test applied to $\log 10 X_{\text {Con }}$ and $\log 10 X_{\mathrm{CSQ}}$. A $P$ value of $\leq 0.05$ was considered to be significant.

\section{Results}

\section{Expression of CSQ1}

CSQ1 contains a highly acidic-rich C-terminal domain, ${ }^{354}$ EDDDDEDDDDDDDD ${ }^{367}$, purported to be a $\mathrm{Ca}^{2+}$ binding motif, and contains residues essential for binding both junctin and trisk95 [15]. To investigate the function of the CSQ1 C-terminal domain, we generated two deletion mutants of GST-tagged rabbit CSQ1 and three alanine substitution mutants. The two CSQ1 deletion mutants were generated by deleting either the whole C-terminal tail $\left(\mathrm{CSQ}_{\triangle \mathrm{C} 14}\right)$ or $50 \%$ of the tail $\left(\mathrm{CSQ}_{\triangle \mathrm{C} 7}\right)$ (Figure 1A). As CSQ $\mathrm{Ca}^{2+}$ binding motifs consist of a pair of acidic residues located close in space (with each pair binding one calcium ion), alternate acidic residues were substituted to disrupt one $\left(C S Q 1_{\mathrm{DA} 1}\right)$, two $\left(\mathrm{CSQ} 1_{\mathrm{DA} 2}\right)$, or three $\left(\mathrm{CSQ}_{\mathrm{DA} 3}\right) \mathrm{Ca}^{2+}$ binding sites within the sequence (Figure 1A). For single channel and ${ }^{45} \mathrm{Ca}^{2+}$ binding studies, CSQ1 constructs were cleaved from the GST by incubation with the serine endopeptidase Factor Xa and purified to homogeneity (Figure 1B).

\section{Effects of C-terminal tail modification on the $\mathrm{Ca}^{2+}$ binding capacity of CSQ}

The $\mathrm{Ca}^{2+}$ binding capacity of the CSQ1 constructs was determined using ${ }^{45} \mathrm{Ca}^{2+}$ binding. $\mathrm{Ca}^{2+}$ binding capacity is dependent on CSQ1 structure and increases sharply as CSQ1 polymerizes. Given that CSQ1's C-terminus is believed to form a large acidic $\mathrm{Ca}^{2+}$ binding pocket upon polymerization [27], it follows that disruption of this pocket would reduce $\mathrm{Ca}^{2+}$ binding capacity. Mutation of one or two acidic residues (CSQ1 $1_{\mathrm{DA} 1}$ and $\mathrm{CSQ}_{\mathrm{DA} 2}$ ) within the $\mathrm{C}$-terminus had no significant effect on $\mathrm{Ca}^{2+}$ binding capacity from 0.1 to $1 \mathrm{mM} \mathrm{Ca}^{2+}$, and the binding curves were similar to that we have previously reported [42], but $C S Q 1_{\text {DA2 }}$ bound significantly less $\mathrm{Ca}^{2+}$ than WT CSQ1 at $2 \mathrm{mM} \mathrm{Ca}^{2+}$ (Figure 2). Mutation of three acidic residues $\left(C S Q 1_{D A 3}\right)$ was sufficient to reduce $\mathrm{Ca}^{2+}$ binding capacity to approximately $70 \%$ of WT CSQ1 at resting $\left[\mathrm{Ca}^{2+}\right]$ of $1 \mathrm{mM}$ and to significantly depress binding capacity at all other $\left[\mathrm{Ca}^{2+}\right]$ tested. Truncation of the C-terminus (CSQ1 ${ }_{\triangle \mathrm{C} 7}$ ) led to a $40 \%$ to $60 \%$ drop in $\mathrm{Ca}^{2+}$ binding capacity at all $\left[\mathrm{Ca}^{2+}\right]$ tested, while removing the entire $\mathrm{C}$-terminus $\left(\mathrm{CSQ}_{\Delta \mathrm{C} 14}\right)$ all but abolished $\mathrm{Ca}^{2+}$ binding (Figure 2). This provides further strong evidence that many of the $\mathrm{C}$-terminal acidic residues of CSQ1 are key to the formation of a $\mathrm{Ca}^{2+}$ binding pocket, which enhances CSQ's $\mathrm{Ca}^{2+}$ binding capacity. 


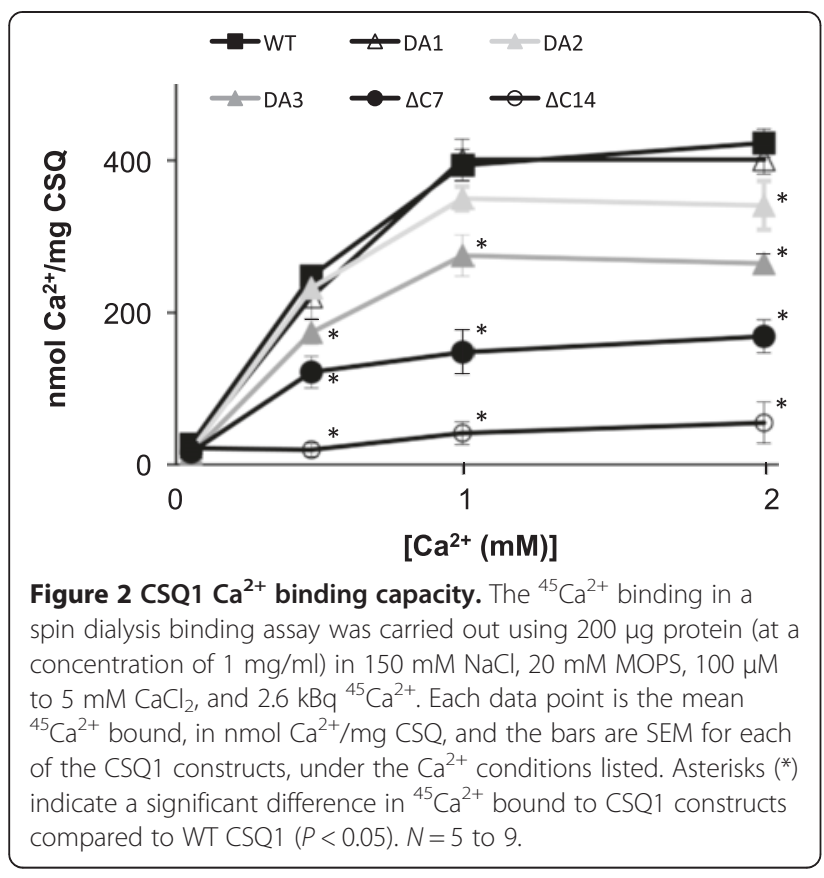

\section{CSQ1 aggregation}

To determine whether mutation of the acidic C-terminus disrupted CSQ1 aggregation, turbidity measurements were performed. CSQ1 and CSQ2 undergo $\mathrm{Ca}^{2+}$-induced compaction or a shift from the proteins soluble to insoluble form [41]. CSQ1 aggregation is measured as turbidity (absorbance at $350 \mathrm{~nm}$ ), which is proportional to the levels of insoluble CSQ1 [40,41]. The turbidity of WT CSQ1 increases sigmoidily across the $\left[\mathrm{Ca}^{2+}\right]$ range tested, reaching a constant concentration of insoluble protein at between 1 and $1.5 \mathrm{mM} \mathrm{Ca}^{2+}$ (Figure 3). Mutation of one or two alternate residues yielded near identical results, while mutation of three residues resulted in a small approximately 20\% decrease in absorbance across $\left[\mathrm{Ca}^{2+}\right]$ 's of 0.7 to $2 \mathrm{mM}$ (Figure 3 ; compare CSQ1 $1_{\mathrm{DA} 3}$ with $\mathrm{WT}, \mathrm{CSQ} 1_{\mathrm{DA} 1}$ and $\left.C S Q 1_{D A 2}\right)$. These data indicate that these residues do not play a major role in $\mathrm{Ca}^{2+}$-induced CSQ1 compaction. $C S Q 1_{\Delta C 7}$ and $C S Q 1_{\Delta C 14}$ displayed marked differences in the $\mathrm{Ca}^{2+}$-dependent aggregation of CSQ1 (Figure 3). $\mathrm{CSQ}_{\Delta \mathrm{C} 7}$ showed some levels of $\mathrm{Ca}^{2+}$-induced aggregation; these were much less than WT, $C S Q 1_{\mathrm{DA} 1}, \mathrm{CSQ} 1_{\mathrm{DA} 2}$, or $\mathrm{CSQ} 1_{\mathrm{DA} 3}$, indicating that residues ${ }^{361}{ }^{D D D D D D D}{ }^{367}$ are important in the formation of the higher molecular weight entities. Remarkably, deleting CSQ1 C-terminus severely disrupted CSQ1 ability to aggregate, presumably by disrupting $\mathrm{Ca}^{2+}$-induced polymerization.

\section{Effects of CSQ modification on in vitro interactions with trisk95 and junctin}

We tested the ability of CSQ1 to associate with trisk95 and junctin via its C-terminal residues, using co-

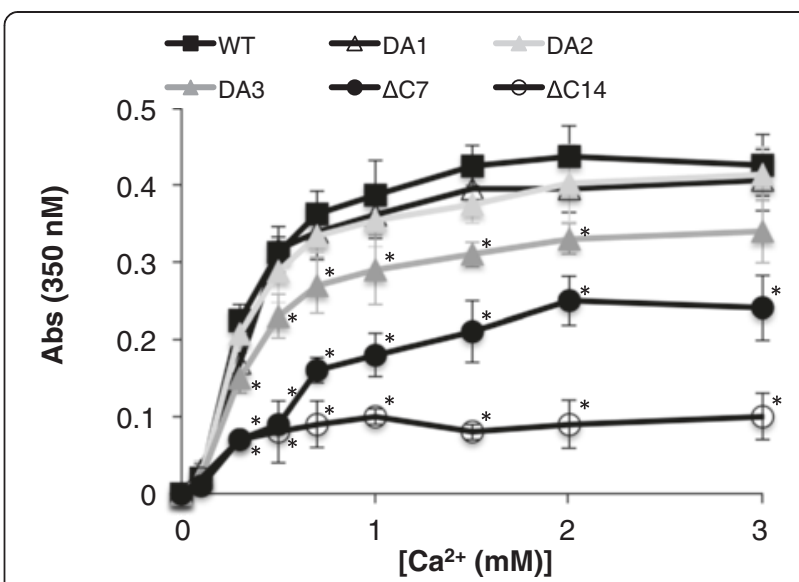

Figure 3 CSQ C-terminal tail contributes to CSQ1 aggregation. CSQ turbidity, an indicator of polymerization and aggregation, is measured as absorbance at $350 \mathrm{~nm}$. Experiments were carried out in a buffer containing $20 \mathrm{mM} \mathrm{MOPS}, 100 \mathrm{mM} \mathrm{KCl}$, and 0 to $3 \mathrm{mM}$ $\mathrm{CaCl}_{2}$. Data is presented as mean $\pm \mathrm{SEM}$ for each of the CSQ1 constructs. Asterisks $\left(^{*}\right)$ indicate average data significantly different $(P \leq 0.05)$ from that of $\mathrm{WT} C \mathrm{CSQ} 1$ at the same $\left[\mathrm{Ca}^{2+}\right]$.

immunoprecipitation. Purified CSQ constructs were coupled to anti-CSQ1/agarose protein A/G, prior to exposure to trisk95 or junctin. As has been previously reported [42], there are significant interactions between WT CSQ1/trisk95 and WT CSQ1/junctin at the resting luminal $\left[\mathrm{Ca}^{2+}\right]$ of $1 \mathrm{mM} \mathrm{Ca}{ }^{2+}$ and ionic strength (150 $\mathrm{mM}$ ) (Figure 4A,C first lane). A substantial interaction between the proteins remained after mutation of one or two alternate residues. There was a small but significant decrease in trisk 95 association with CSQ1 $1_{\mathrm{DA} 3}$ (Figure $4 \mathrm{~A}, \mathrm{D}$ ), indicating that ${ }^{363} \mathrm{D}$ may play a minor role in the trisk95-CSQ1 association. This result suggests that these three alternate $\mathrm{C}$-terminal residues are not critical for the interaction with either trisk95 or junctin.

The deletion constructs CSQ1 $1_{\Delta C 7}$ and $C S Q 1_{\Delta C 14}$ reveal that the overall $\mathrm{C}$-terminal tail domain heavily influences trisk95's interaction with CSQ1. Deletion of the entire C-terminal tail abolished CSQ1 association with trisk95 (Figure 4A,D). Interestingly, there is a significantly reduced band of trisk 95 indicating minimal association with the $\mathrm{CSQ}_{\triangle \mathrm{C} 7}$ construct (Figure 4A,D), indicating that residue ${ }^{361} \mathrm{DDDDDDD}^{367}$ contributes significantly to the trisk95-CSQ1 interaction, with a minor contribution from ${ }^{363} \mathrm{D}$. The reduced CSQ1-trisk95 interaction may be due to altered $\mathrm{Ca}^{2+}$ sensitivity of the trisk95-CSQ1 interaction, which has been shown to be highly $\mathrm{Ca}^{2+}$-dependent [15]. There is only modest trisk95CSQ1 binding at resting luminal $\left[\mathrm{Ca}^{2+}\right](1 \mathrm{mM})$ and much higher trisk95-CSQ1 association at lower $\mathrm{Ca}^{2+}$ concentrations (approximately $100 \mu \mathrm{M}$ ) [15]. However, lowering $\left[\mathrm{Ca}^{2+}\right]$ to $100 \mu \mathrm{M}$ did not significantly alter the degree of 

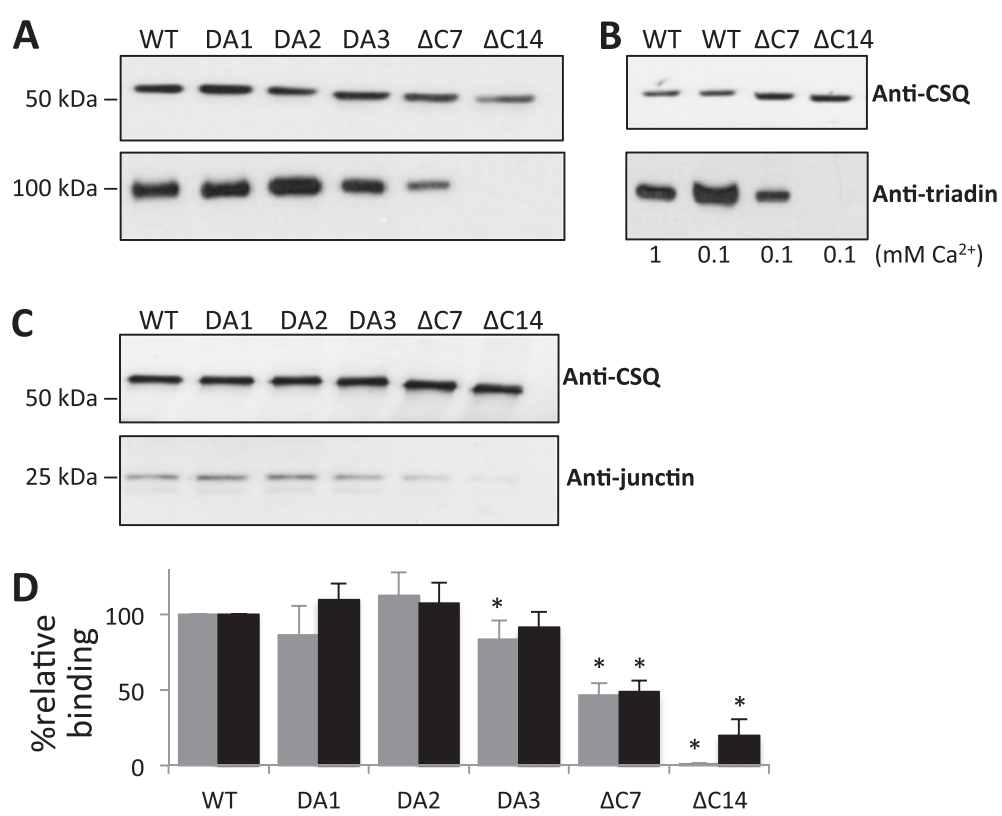

Figure 4 In vitro CSQ1 binding to trisk95 and junctin. CSQ1 IP. Western blot showing binding of junctin and trisk95 to CSQ1 coupled to anti-CSQ1/protein A/G sepharose. (A) and (C). Binding of trisk95 (A) and junctin (C) at $1 \mathrm{mM} \mathrm{Ca}{ }^{2+}$ to the following CSQ constructs, from left to

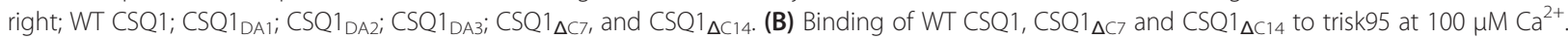
WT CSQ1 binding to trisk95 at $1 \mathrm{mM} \mathrm{Ca}{ }^{2+}$ is shown in in the first lane for comparison. Each blot in (A) to (C) was immunoprobed with antibodies against CSQ1, trisk95, and junctin. Binding was repeated three to four times. (D) Quantitation of trisk95 and junctin association with CSQ1 Cterminal mutants at $1 \mathrm{mM} \mathrm{Ca}{ }^{2+}$. The relative percentage binding of trisk95 (gray bin) and junctin (black bin) is presented as mean \pm SE. Data is presented relative to the association of trisk95 and junctin with WT CSQ1. No band was detected for trisk95 binding to CSQ1 $\triangle \mathrm{C} 14$. Asterisks $\left(^{*}\right.$ ) indicate average data significantly different $(P \leq 0.05)$ from binding of trisk95 or junctin to WT CSQ1. Molecular weight markers are to the left of the blots in $(\mathbf{A})$ and $(\mathbf{C})$.

trisk95 association with $\mathrm{CSQ}_{\triangle \mathrm{C} 7}$ or $\mathrm{CSQ}_{\Delta \mathrm{C} 14}$ (compare $\mathrm{CSQ}_{\Delta \mathrm{C} 7}$ and $\mathrm{CSQ} 1_{\Delta \mathrm{C} 14}$ in Figure $4 \mathrm{~A}\left(1 \mathrm{mM} \mathrm{Ca}^{2+}\right)$ with $\mathrm{CSQ}_{\Delta \mathrm{C} 7}$ and $\mathrm{CSQ} 1_{\Delta \mathrm{C} 14}$ in Figure 4B $\left.(100 \mu \mathrm{M})\right)$. Therefore, the impaired interaction is not due to a shift in $\mathrm{Ca}^{2+}$ dependence of the association but most likely due to deletion of the interaction site on CSQ1 for trisk95.

In contrast to the effects on CSQ/trisk95 binding, deletion of the C-terminal tail of CSQ1 severely impeded, but did not abolish, junctin association with CSQ1 (Figure 4C, D). Both the $C S Q 11_{\Delta C 7}$ and $C S Q 11_{\Delta C 14}$ constructs bound approximately $50 \%$ to $80 \%$ less junctin than did WT CSQ1 (Figure 4C; compare WT with CSQ1 $1_{\Delta C 7}$ and $\left.\mathrm{CSQ}_{\triangle \mathrm{C} 14}\right)$. This implies that the C-terminal tail forms a major part of the junctin binding motif but does not constitute the entire binding domain.

\section{Effects of CSQ1 modification on the regulation of RyR1 channels by CSQ1}

The functional consequence of the CSQ1 C-terminal mutations on RyR1 regulation by CSQ1 was studied in lipid bilayers. At a physiological resting $\left[\mathrm{Ca}^{2+}\right]$ of $1 \mathrm{mM}$, CSQ1 polymers are tethered to the RyR1 through its interactions with trisk95 and junctin, allowing CSQ1 to inhibit native rabbit skeletal RyR1, specifically through its association with junctin [39]. Thus, it is likely that mutation of residues that reduce $\mathrm{Ca}^{2+}$ binding capacity and/or inhibit interactions with junctin would alter CSQ1's functional effect on RyR1 gating.

Native skeletal rabbit SR vesicles (which contain the RyR1 and its full complement of associated co-proteins) were incorporated into lipid bilayers, and baseline activity was recorded after addition of $2 \mathrm{mM}$ cis ATP and 4.5 $\mathrm{mM}$ trans BAPTA (to lower trans $\mathrm{Ca}^{2+}$ to $100 \mathrm{nM}$, that is, a sub $\mathrm{Ca}^{2+}$-activated level; Figure $5 \mathrm{~A}$, top panel). After approximately 3 to $5 \mathrm{~min}$ of stable baseline recording, the $\mathrm{Cs}^{+}$concentration in the trans chamber was increased to $500 \mathrm{mM}$ for $5 \mathrm{~min}$ to strip endogenous CSQ1 from the native RyR1 [7]. The trans chamber was then perfused with trans solution to remove dissociated CSQ1 and to reduce trans $\left[\mathrm{Cs}^{+}\right]$to $250 \mathrm{mM}$. Dissociation of endogenous inhibitor CSQ1 from RyR1 (to yield CSQ-dissociated RyR1) caused an increase in channel open probability $\left(P_{o}\right)$, which is sustained after the removal of high trans $\mathrm{Cs}^{+}$(Figure 5A, middle trace). As previously reported [7], re-association of WT CSQ1 with the luminal face of the CSQ-dissociated RyR1, caused significant inhibition of RyR1 activity, restoring channel activity to the baseline level (Figures 5A and 6A).

Re-association of each of CSQ $1_{\mathrm{DA} 1}, \mathrm{CSQ} 1_{\mathrm{DA} 2}$, and CSQ1 $1_{\text {DA3 }}$ with CSQ-dissociated RyR1 also inhibited 
A

Control native RyR1

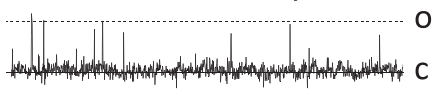

CSQ1 dissociation

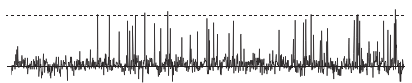

$+16 \mu \mathrm{g} / \mathrm{ml}$ WT CSQ1

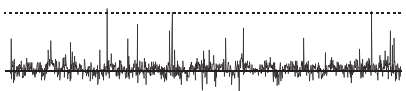

C

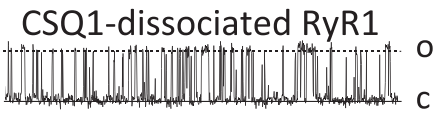

$+16 \mu \mathrm{g} / \mathrm{ml} \mathrm{CSQ}_{\Delta \mathrm{C} 7}$

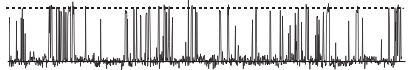

B

CSQ1-dissociated RyR1

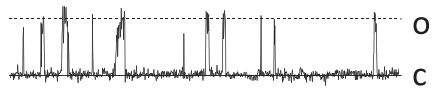

$+16 \mu \mathrm{g} / \mathrm{ml} \mathrm{CSQ}_{\mathrm{DA} 3}$

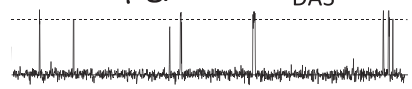

1s

D

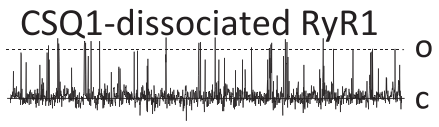

$+16 \mu \mathrm{g} / \mathrm{ml} \mathrm{CSQ}_{\Delta \mathrm{C} 14}$

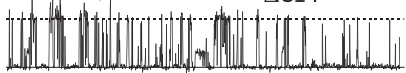

Figure 5 Deletion of the C-terminal tail, but not sequential mutation, results in ablation of CSQ1 regulation of RyR1 gating.

(A) to (D). Records of $3 \mathrm{~s}$ of single channel activity, where channel opening is upward from zero current (c, continuous line) to maximum open conductance (o, broken line) at $+40 \mathrm{mV}$. (A) Top trace - control activity, with $2 \mathrm{mM}$ cis ATP and $100 \mathrm{nM}$ cis Ca ${ }^{2+}$ free. Middle trace - channel activity increased approximately 2 min after raising trans Cs to $500 \mathrm{mM}$, indicative of endogenous CSQ1 dissociation [33]. Bottom trace following perfusion of the trans chamber with control trans solution, and subsequent addition of $16 \mathrm{mg} / \mathrm{ml}$ WT CSQ1. (B) to (D) Response of CSQ1-dissociated native RyR1 before (top) and after (bottom) addition of $16 \mathrm{mg} / \mathrm{ml}$ trans CSQ1 $1_{\triangle \triangle 3}$ (B), CSQ1 ${ }_{\triangle C 7}$ (C), and CSQ1 $1_{\triangle C 14}$ (D).

channel activity. Adding $16 \mu \mathrm{g} / \mathrm{ml} \mathrm{CSQ} 1_{\mathrm{DA} 1}, \mathrm{CSQ} 1_{\mathrm{DA} 2}$, or CSQ1 $1_{\mathrm{DA} 3}$ caused a 2.7 -fold, 2.4-fold, and 2.2-fold decrease in channel activity, respectively (Figures $5 \mathrm{~B}$ and $6 \mathrm{~A}, \mathrm{~B}, \mathrm{C}, \mathrm{D}$; Table 1). The degree of inhibition by these three constructs is reminiscent of the $>2$-fold decrease in channel activity induced by WT CSQ1 (Table 1 and [7]).

The decrease in $P_{o}$ in the presence of WT CSQ1 and alanine substituted mutants $C S Q 1_{\mathrm{DA} 1}-\mathrm{CSQ} 1_{\mathrm{DA} 3}$ is due to a significant decrease in mean open time $\left(T_{o}\right)$ (Figure 6B; Table 1). Similar decreases in $\left(T_{o}\right)$ were observed upon reassociating the CSQ1 alanine mutants (Figure 6B; Table 1). There were also significant increases in mean closed times $\left(T_{c}\right)$ of the channels, in line with those recorded in the presence of WT CSQ1 (Figure 6C; Table 1). As a result of the opposing changes in $T_{o}$ and $T_{c}$, there was no change in the overall frequency of opening (Figure 6D).

In contrast to substitution within the final five Cterminal residues $\left(\mathrm{CSQ} 1_{\mathrm{DA} 3}\right)$, deletion of the final seven C-terminal acidic residues reduced CSQ1's ability to inhibit RyR1 channels (Figures 5C and 6A,B,C,D; Table 1). While the CSQ1 ${ }_{\Delta \mathrm{C} 7}$ mutant inhibited channels, the inhibition was significantly less than the potent inhibition caused by WT CSQ1 and CSQ1 $1_{\mathrm{DA} 1}-\mathrm{CSQ} 1_{\mathrm{DA} 3}$. The decrease in $P_{o}$ was accompanied by significant changes in $T_{o}$ and $T_{c}$ (Figure 6B,C; Table 1). This data correlates with the reduced ability of this construct to induce $\mathrm{Ca}^{2+}$ compaction (Figure 3 ) and to bind to junctin (Figure 4), which communicates CSQ1 signaling to RyR1 [39]. Removal of the entire C-terminal tail abolished CSQ1's ability to inhibit the RyR1 channels (Figures 5D and 6A,B,C,D; Table 1). Indeed, CSQ1 ${ }_{\Delta C 14}$ evoked a small but significant activation of RyR1. This activation is similar to the activation seen when CSQ1 is added to purified RyR 1 , that is, only seen when trisk 95 and junctin are absent $[7,43]$ and indicative of a direct, but probably non-physiological, interaction between CSQ1 and RyR1.

To investigate the nature of the small RyR1 activation by CSQ $1_{\triangle \mathrm{C} 14}$, we examined its effect on purified RyR1 (Figure 7). There was no contaminant trisk95, junctin, or CSQ1 in this sample (Figure 7D), so that any effects of $\mathrm{CSQ}_{\Delta \mathrm{C} 14}$ would be due to its association directly with RyR1, rather than via the anchoring proteins. Purified RyR1 activity rose significantly approximately 1.9- 

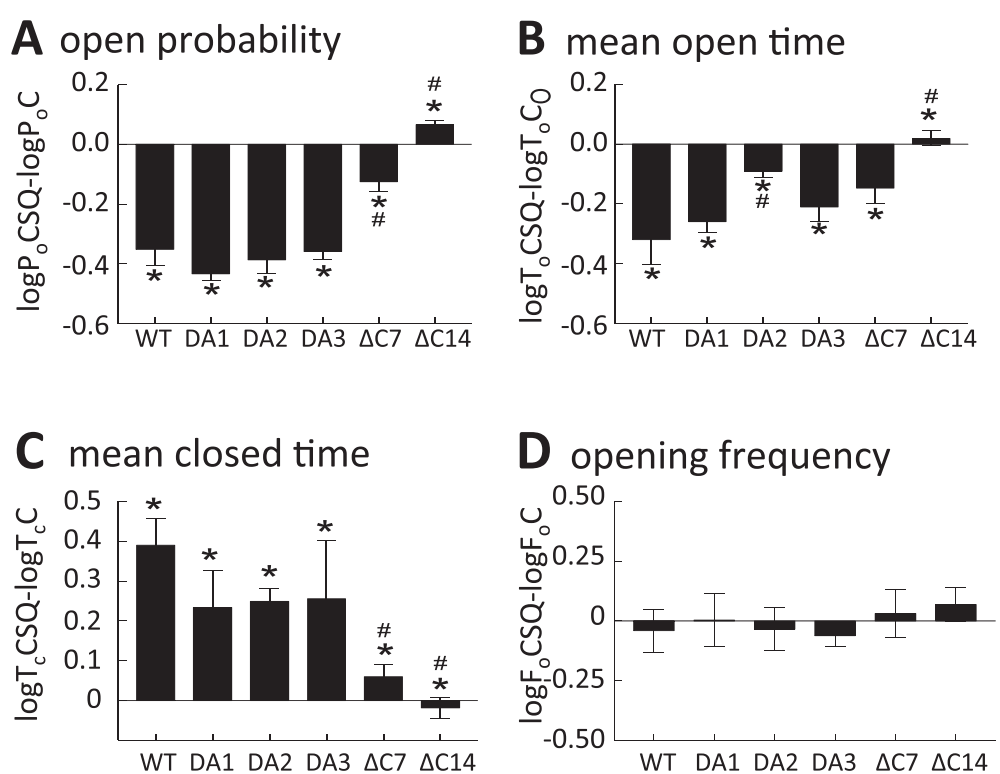

Figure 6 Ablation of CSQ1-induced RyR1 regulation is due to significant changes in channel $P_{o}, T_{o}$, and $T_{c}$. Average relative data (relative to activity before the addition of CSQ1 constructs; $N=8$ ) showing $P_{0}, T_{0}, T_{C}$ and $F_{0}$. $(\mathbf{A})$ Relative $P_{0}\left(\log\right.$ rel $\left.P_{0}\right)$ is the average of differences between the $\log 10$ of $P_{0}$ in the presence of CSQ1 constructs $\left(\log P_{o C S Q}\right)$ and $\log 10$ of the control $P_{0}\left(\log P_{o}\right.$ con; in the absence of CSQ1) for each channel. (B) The relative mean open time $\left(\log r e l T_{0}\right)$ is $\log T_{\text {ocse }}-\log T_{\text {ocon. }}$ (C) The relative mean closed time $\left(\log r e l T_{c}\right)$ is $\log T_{c c s Q}-\log T_{c c o n}$. (D) The relative mean open frequency (log rel $\left.F_{0}\right)$ is $\log F_{o c s e}-\log F_{o c o n}$. Average data significantly different $(P \leq 0.05)$ from channel activity recorded in the absence of WT CSQ1 is indicated by asterisk $\left(^{*}\right)$ and in the presence of WT CSQ1 indicated by crosshatch (\#). Data were recorded at +40 and $-40 \mathrm{mV}$.

fold after the trans addition of $16 \mathrm{mg} / \mathrm{ml} \mathrm{CSQ} 1_{\Delta \mathrm{C} 14}$ (Figure 7A,B), although the degree of purified RyR1 activation was not as high as the approximately 2.8 fold activation induced by WT CSQ1 (Figure 7 and [7]). In addition, affinity chromatography shows that both the WT CSQ1 and CSQ1 ${ }_{\triangle \mathrm{C} 14}$ bound to purified RyR1 (Figure 7C). This indicates that although there was no difference in the ability of CSQ1 to bind directly to RyR1 in the presence or absence of the C-terminal tail, full activation of RyR1 by CSQ1 depends on binding to residues in both the C-terminal domain of CSQ1 and in the $\mathrm{N}$-terminal domains. We have previously suggested that despite CSQ1 causing a modest activation of purified RyR1 in the bilayer, it is the overwhelming inhibition of native RyR1 (through the CSQ1-junctinRyR1 interaction; [39]) which drives the overall effect of CSQ1 in the cell, which would acts as a brake on SR $\mathrm{Ca}^{2+}$ release.

Table 1 Comparison of changes in RyR1 channel gating parameters induced by association of CSQ1 constructs

\begin{tabular}{|c|c|c|c|c|c|c|c|}
\hline & & \multicolumn{6}{|l|}{$(X \pm$ SEM $)$} \\
\hline & & WT CSQ & $\mathrm{CSQ}_{\mathrm{DA} 1}$ & CSQ1 ${ }_{\mathrm{DA} 2}$ & $\mathrm{CSQ}_{\mathrm{DA} 3}$ & $\mathrm{CSQ}_{\triangle C 7}$ & $\mathrm{CSQ}_{\Delta \mathrm{C} 14}$ \\
\hline RyR1-CSQ & $P_{0}$ & $0.19 \pm 0.02$ & $0.19 \pm 0.03$ & $0.17 \pm 0.07$ & $0.15 \pm 0.04$ & $0.12 \pm 0.01$ & $0.12 \pm 0.02$ \\
\hline RyR1 + CSQ & $P_{0}$ & $0.08 \pm 0.01^{*}$ & $0.07 \pm 0.01^{*}$ & $0.06 \pm 0.02^{*}$ & $0.07 \pm 0.01^{*}$ & $0.10 \pm 0.01^{*} \#$ & $0.15 \pm 0.01 * \#$ \\
\hline RyR1-CSQ & $T_{0}$ & $4.93 \pm 1.40$ & $3.55 \pm 0.26$ & $3.44 \pm 0.28$ & $3.08 \pm 0.42$ & $3.80 \pm 0.48$ & $7.09 \pm 1.99$ \\
\hline RyR1 + CSQ & $T_{0}$ & $2.43 \pm 0.53^{*}$ & $1.96 \pm 0.15^{*}$ & $2.78 \pm 0.23^{*}$ & $1.99 \pm 0.36^{*}$ & $2.67 \pm 0.30^{*}$ & $6.70 \pm 1.76 \#$ \\
\hline RyR1-CSQ & $T_{c}$ & $18.73 \pm 4.02$ & $25.03 \pm 4.95$ & $22.20 \pm 6.40$ & $33.85 \pm 5.37$ & $115.78 \pm 38.29 \#$ & $40.62 \pm 7.81 \#$ \\
\hline RyR1 + CSQ & $T_{c}$ & $33.41 \pm 4.97^{*}$ & $39.74 \pm 10.72^{*}$ & $38.01 \pm 5.78^{*}$ & $46.14 \pm 5.86 \#^{*}$ & $115.69 \pm 50.11 \#$ & $36.95 \pm 10.40$ \\
\hline RyR1-CSQ & $F_{o}$ & $34.15 \pm 2.72$ & $39.68 \pm 3.27$ & $41.78 \pm 5.65$ & $32.97 \pm 5.95$ & $16.9 \pm 4.50 \#$ & $26.18 \pm 7.95$ \\
\hline RyR1 + CSQ & $F_{0}$ & $27.32 \pm 5.66$ & $36.37 \pm 8.20$ & $39.20 \pm 7.20$ & $27.76 \pm 5.79$ & $17.46 \pm 4.40 \#$ & $25.18 \pm 6.49$ \\
\hline
\end{tabular}

Endogenous CSQ1 was first dissociated from RyR1. The first row for each parameter shows average data for channel activity following dissociation of endogenous CSQ1 (RyR1-CSQ1) and before addition of the recombinant CSQ1 construct. The second row in each parameter shows average data after addition of the indicated construct. Parameters are open probability $\left(P_{o}\right)$, open time $\left(T_{o}\right)$, closed time $\left(T_{c}\right)$, and open frequency $\left(F_{o}\right)$, which are the mean $\pm \operatorname{SE}(N=7$ to 12$)$ of combined data recorded at +40 and $-40 \mathrm{mV}$. Asterisks $\left(^{*}\right)$ indicate average parameter significantly different $(P \leq 0.05)$ from that recorded in the absence of CSQ1, and crosshatch $(\#)$ indicates average parameter significantly different $(P \leq 0.05)$ from that recorded after addition of WT CSQ1. 


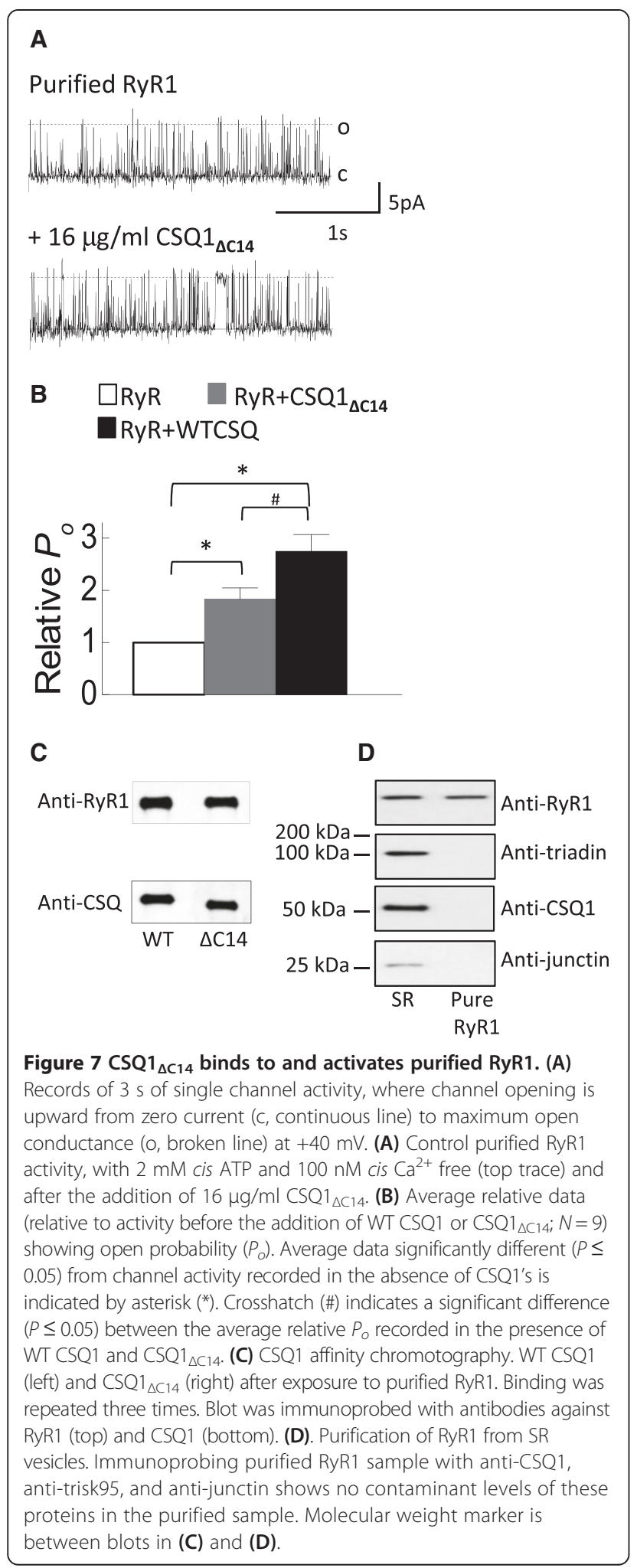

\section{Discussion}

\section{Overview}

Here, we present evidence that the $\mathrm{C}$-terminal tail of CSQ1 forms the primary binding pocket for $\mathrm{Ca}^{2+}$ ions and that it contains the CSQ1 binding sites for trisk95 and junctin and for functional interactions with RyR1. This is also the first evaluation of the influence of specific acidic residues on the functional characteristics of CSQ1. Our novel data indicates the extent to which specific acidic residues in CSQ1's C-terminal tail influence the $\mathrm{Ca}^{2+}$ binding capacity and $\mathrm{Ca}^{2+}$-induced aggregation of CSQ1, its ability to bind to trisk95 and junctin and its ability to inhibit RyR1. In summary, $\mathrm{Ca}^{2+}$ binding declines with progressive removal of acidic residues, and all 14 acidic residues are required for the full $\mathrm{Ca}^{2+}$ binding capacity of the wild-type protein. Deletion of one to three of the acidic residues has little effect on $\mathrm{Ca}^{2+}$-induced compaction or CSQ1 association with trisk95 and junctin and does not alter the inhibitory action on RyR1 of the CSQ1 binding to junctin. CSQ1 aggregation, binding of trisk95 and junctin to CSQ1, and the inhibitory effect of the binding on RyR1 activity are severely disrupted by deletion of seven of the acidic residues and are all but abolished by deletion of all $14 \mathrm{C}$-terminal residues.

\section{$\mathrm{CSQ} \mathrm{Ca}^{2+}$ binding capacity}

The $\mathrm{Ca}^{2+}$ binding capacity of CSQ1 decreased when two or more residues within the acidic $\mathrm{C}$-terminal tail were modified or deleted. CSQ1's moderate $\mathrm{Ca}^{2+}$ binding capacity has been thought to depend on CSQ1's polymerization which occurs at relatively high $\left[\mathrm{Ca}^{2+}\right]$ $(>0.5 \mathrm{mM})$. This model is based on the published crystal structure of rabbit skeletal CSQ1 but is not supported by the crystal structure as residues 352 to 367 are not observed in the electron density mapping (reviewed in [33]). CSQ1 dimers and polymers condense at $\left[\mathrm{Ca}^{2+}\right]$ s between $100 \mu \mathrm{M}$ and $1 \mathrm{mM}$ with a cellular ionic strength of $150 \mathrm{mM}$ [6]. The $\mathrm{Ca}^{2+}$ dependence of CSQ1's structure suggests that $\mathrm{Ca}^{2+}$ may act as a "glue", interacting with key acidic residues when a polymer is formed. It is further hypothesized that residues within the C-terminus form a $\mathrm{Ca}^{2+}$ binding sink within the structured protein which is stabilized by the formation of three salt bridges $\left({ }^{215} \mathrm{E}^{-86} \mathrm{~K},{ }^{216} \mathrm{E}^{24} \mathrm{~K}\right.$, and $\left.{ }^{169} \mathrm{E}^{-85} \mathrm{~K}\right)$ [27]. The linear sequence of full-length CSQ1 cannot account for its reported $\mathrm{Ca}^{2+}$ binding capacity, of $34 \mathrm{Ca}^{2+}$ ions per monomer at resting $(1 \mathrm{mM})\left[\mathrm{Ca}^{2+}\right][4]$. There are insufficient acidic residues on CSQ1 to form the 34 acidic doublets, assuming that one acidic double is required to bind each $\mathrm{Ca}^{2+}$ ion [44]. The $\mathrm{Ca}^{2+}$ sink hypothesis was recently refined, with simulation model data showing that $\mathrm{Ca}^{2+}$ preferentially saturates the $\mathrm{C}$-terminal tail and induces protein polymerization which stabilizes the formation of many $\mathrm{Ca}^{2+}$ binding sites on CSQ1's surface [32] which 
and could rationally account for the reported $\mathrm{Ca}^{2+}$ binding capacity. Our data provides the first experimental evidence supporting this refined hypothesis.

Furthermore, the mutation of three acidic residues in the C-terminal tail could only account for the loss of 3 of the $34 \mathrm{Ca}^{2+}$ ions bound per monomer of CSQ1, yet $\mathrm{Ca}^{2+}$ binding data illustrates an approximately $45 \%$ loss of $\mathrm{Ca}^{2+}$ binding capacity. One interpretation of our data is that these residues are important in stabilization of the $\mathrm{Ca}^{2+}$ binding pocket formed upon CSQ1 polymerization in which the ratio of $\mathrm{Ca}^{2+}$ ions to acidic doublets residues is $\gg 1$. This is supported by data showing CSQ1 structure and $\mathrm{Ca}^{2+}$ binding are drastically altered when the whole C-terminal tail is deleted (Figure 2 and $[15,29]$ ) and the inability of $\mathrm{CSQ}_{\triangle \mathrm{C} 14}$ to form polymers (Figure 3) under our experimental conditions. CSQ1 is reported to be the key luminal $\mathrm{Ca}^{2+}$ sensor for the RyR1 and to guide RyR1's response to the fluctuations in luminal $\left[\mathrm{Ca}^{2+}\right]$ that occur during contraction and relaxation [6,8,34]. CSQ1 binds and releases $\mathrm{Ca}^{2+}$ in response to store load and to maintain free $\mathrm{Ca}^{2+}$ at approximately $1 \mathrm{mM}$ and allows CSQ1 to sense the level of $\mathrm{Ca}^{2+}$ inside the SR. Given that mutation and deletion of the $\mathrm{C}$-terminus has a profound effect on $\mathrm{Ca}^{2+}$ binding capacity, it is likely that the $\mathrm{C}$-terminal tail is important in communicating luminal $\left[\mathrm{Ca}^{2+}\right]$ to RyR1.

\section{Loss of CSQ1 binding to trisk95 and junctin}

It was not surprising that the absence of the C-terminal tail impeded CSQ1-trisk95 association as the CSQ1 binding site for trisk 95 has previously been localized to residues within the $\mathrm{C}$-terminal tail [16]. Further dissection illustrates that residues 363, 365, and 367 do not play a pivotal role in this association, although comparison of binding of CSQ1 $1_{\mathrm{DA} 2}$ and $C S Q 1_{\mathrm{DA} 3}$ do suggest a minor role for ${ }^{363} \mathrm{D}$. It appears that residues 354 to 362 are essential in forming CSQ1's trisk95 binding site.

It is significant that a modest amount of junctin was able to bind to $C S Q 1_{\triangle C 14}$, given that others have reported that the C-terminal domain of CSQ1 is the sole binding site for junctin in skeletal muscle [15]. This is consistent with the fact that more than one binding site on CSQ1 may be involved in its association with junctin in skeletal muscle, as with cardiac CSQ2 [13]. It is likely that a binding motif, in N-terminal domains of CSQ1, contributes to junctin association and would account the fraction of junctin binding remaining with $\mathrm{CSQ}_{\Delta \mathrm{C} 7}$ and $\mathrm{CSQ}_{\triangle \mathrm{C} 14}$.

Loss of CSQ1 regulatory function of RyR1 channel activity The significant decrease in CSQ1's ability to inhibit RyR1 activity following deletion of 361 to 367, but that substitution of residues 363,365 , and 367 maintain normal RyR1 regulation implies that residues 361, 362, 364, and 366 contribute to maintaining the efficiency of
CSQ1's regulation of RyR1 [9]. The abolition of RyR1 inhibition by CSQ1 when the C-terminal tail was removed confirms both that this tail is essential in CSQ1's role in inhibition of $\mathrm{Ca}^{2+}$ release through RyR1 and an important role for residues 354 to 360 . CSQ1 inhibition of RyR1 activity is mediated via a RyR1/junctin/CSQ1 interaction, and not through RyR1/trisk95/CSQ1 [39]. Therefore, it is curious that CSQ1 inhibition of the channel is lost despite the remaining modest association of junctin with CSQ1 ${ }_{\Delta \mathrm{C} 14}$. It is possible that CSQ1's function as a channel inhibitor is directly related to its $\mathrm{Ca}^{2+}$ binding capacity and/or structure, which is severely reduced when the $\mathrm{C}$-terminal tail is removed from CSQ1 (Figures 2 and 3).

\section{CSQ1 activation of RyR1 - not a physiological regulatory mechanism?}

CSQ1 $1_{\triangle \mathrm{C} 14}$ increases the activity of native RyR1 (Figure 6), and both WT CSQ1 $[7,43]$ and CSQ1 ${ }_{\Delta C 14}$ activate purified RyR1 (Figure 7). It is likely that this activation is relatively unimportant physiologically, as full-length CSQ1 addition to RyR1 in the presence of anchors trisk 95 and junctin results in a strong channel inhibition. In light of this, native RyR1 activation by CSQ1 ${ }_{\Delta \mathrm{C} 14}$ can be explained in either of two ways. Firstly, WT CSQ1 associated with junctin exerts a dominant inhibitory effect on RyR1 gating, so that channel inhibition overshadows activation arising from the direct RyR1-CSQ1 association. When the binding site on CSQ1 for junctin is compromised in $C S Q 1_{\triangle C 14}$, channel activation by the direct CSQ1-RyR1 coupling is unmasked. On the other hand, the binding site for WT CSQ1 on RyR1 may be occluded by CSQ1's interaction with trisk95 and/or junctin. Thus, the reduced CSQ1 $1_{\triangle \mathrm{C} 14}$ association with trisk95 and/or junctin may expose the binding site on RyR1 for CSQ1, allowing channel activation when $\mathrm{CSQ}_{\triangle \mathrm{C} 14}$ is added to the trans chamber.

\section{Conclusions}

CSQ1 is unarguably the major the $\mathrm{Ca}^{2+}$ buffer inside the SR. In addition, CSQ1 is both an inhibitor of native RyR1 under resting conditions and also a luminal $\mathrm{Ca}^{2+}$ sensor for the channel, so that it may act as a brake on RyR1 $\mathrm{Ca}^{2+}$ release in times of low store load [7,9]. As mentioned above, CSQ1 has been thought to regulate RyR1 via interactions with trisk95 and junctin. Our previous single channel data suggests that junctin, but not trisk95, is the key intermediate protein in RyR1 inhibition [39], although evidence from one trisk 95 and junctin knockout study suggests that trisk95 is the preferential anchor for CSQ1 [45]. On the other hand, studies using myotubes deficient of trisk 95 and junctin confirm our observations that junctin's primary role is in communication of luminal $\mathrm{Ca}^{2+}$ to RyR1 [46]. It 
remains possible that anchoring and functional regulation are in fact separate processes. Regardless, CSQ1 undisputedly plays an important role in regulating RyR1 and in excitation-contraction coupling. The essential nature of CSQ1 is illustrated in CSQ1-null mice, which exhibit increased susceptibility to stress in a similar manner to exertional/environmental heat stroke and to human malignant hyperthermia $(\mathrm{MH})$ a life-threatening hypermetabolic disorder induced by treatment with volatile anesthetics and the muscle relaxant succinylcholine $[10,47,48]$. This complex phenotype is likely initiated by abnormal $\mathrm{Ca}^{2+}$ handling by the SR, due to lack of CSQ1 inhibition on RyR1 activity [47].

\section{Abbreviations \\ Con: control; CSQ: calsequestrin; CSQ1: calsequestrin type 1; $F_{0}$ : open frequency; $l_{F}^{\prime}$ : fractional mean current; $\mathrm{kD}$ : dissociation constant; $P_{\mathrm{o}}$ : open probability; RyR: ryanodine receptor; RyR1: ryanodine receptor type 1; SR: sarcoplasmic reticulum; Trisk95: triadin skeletal muscle 95 kDa; $T_{0}$ : open time; $T_{c}$ : close time.}

\section{Competing interests}

The authors declare that they have no competing interests.

\section{Authors' contributions}

NAB conceived the study, undertook the experimentation, participated in its design and coordination, and drafted the manuscript. AFD conceived the study, participated in its design and coordination, and drafted the manuscript. Both authors read and approved the final manuscript.

\section{Acknowledgements}

We thank S Pace and J Stivala for the preparation of SR vesicles and purification of RyR1. We thank M. Varsányi (Ruhr Universität, Bochum, Germany) for providing the WT CSQ1 construct. This work was supported by the Australian Research Council (DP1094219 to AFD and NAB) and a NHMRC Career Development Award (NAB).

\section{Received: 31 October 2014 Accepted: 14 January 2015}

Published online: 22 February 2015

\section{References}

1. Royer L, Rios E. Deconstructing calsequestrin. Complex buffering in the calcium store of skeletal muscle. J Physiol. 2009;587(Pt 13):3101-11.

2. Murphy RM, Larkins NT, Mollica JP, Beard NA, Lamb GD. Calsequestrin content and SERCA determine normal and maximal $\mathrm{Ca}^{2+}$ storage levels in sarcoplasmic reticulum of fast- and slow-twitch fibres of rat. J Physiol. 2009:587(Pt 2):443-60.

3. MacLennan DH, Wong PT. Isolation of a calcium-sequestering protein from sarcoplasmic reticulum. Proc Natl Acad Sci U S A. 1971;68:1231-5.

4. Park IY, Kim E, Park H, Fields K, Dunker KA, Kang C. Interaction between cardiac calsequestrin and drugs with known cardiotoxicity. Mol Pharmacol. 2004;67(4):97-104.

5. Shin DW, Pan Z, Kim EK, Lee JM, Bhat MB, Parness J, et al. A retrograde signal from calsequestrin for the regulation of store-operated $\mathrm{Ca}^{2+}$ entry in skeletal muscle. J Biol Chem. 2003;278(5):3286-92.

6. Wei L, Hanna AD, Beard NA, Dulhunty AF. Unique isoform-specific properties of calsequestrin in the heart and skeletal muscle. Cell Calcium. 2009;45(5):474-84.

7. Beard NA, Sakowska MM, Dulhunty AF, Laver DR. Calsequestrin is an inhibitor of skeletal muscle ryanodine receptor calcium release channels. Biophys J. 2002;82(1):310-20.

8. Gyorke I, Hester NA, Jones LR, Gyorke $S$. The role of calsequestrin, triadin, and junctin in conferring cardiac ryanodine receptor responsiveness to luminal calcium. Biophys J. 2004;86:2121-8.

9. Wei L, Varsanyi M, Dulhunty AF, Beard NA. The conformation of calsequestrin determines its ability to regulate skeletal ryanodine receptors. Biophys J. 2006;91(4):1288-301.
10. Protasi F, Paolini C, Dainese M. Calsequestrin-1: a new candidate gene for malignant hyperthermia and exertional/environmental heat stroke. J Physiol. 2009:587(Pt 13):3095-100.

11. Glover L, Culligan K, Cala S, Mulvey C, Ohlendieck K. Calsequestrin binds to monomeric and complexed forms of key calcium-handling proteins in native sarcoplasmic reticulum membranes from rabbit skeletal muscle. Biochim Biophys Acta. 2001;1515(2):120-32.

12. Guo W, Campbell KP. Association of triadin with the ryanodine receptor and calsequestrin in the lumen of the sarcoplasmic reticulum. J Biol Chem. 1995;270:9027-30

13. Kobayashi YM, Alseikhan BA, Jones LR. Localization and characterization of the calsequestrin-binding domain of triadin 1. Evidence for a charged betastrand in mediating the protein-protein interaction. J Biol Chem. 2000;275 (23):17639-46.

14. Mitchell $\mathrm{RD}$, Simmerman $H K$, Jones $L R$. $\mathrm{Ca}^{2+}$ binding effects on protein conformation and protein interactions of canine cardiac calsequestrin. J Biol Chem. 1988;263(3):1376-81.

15. Shin DW, Ma J, Kim DH. The asp-rich region at the carboxyl-terminus of calsequestrin binds to $\mathrm{Ca}^{2+}$ and interacts with triadin. FEBS Lett. 2000;486:178-82.

16. Zhang L, Kelley J, Schmeisser G, Kobayashi YM, Jones LR. Complex formation between junctin, triadin, calsequestrin, and the ryanodine receptor. Proteins of the cardiac junctional sarcoplasmic reticulum membrane. J Biol Chem. 1997;272:23389-97.

17. Buck ED, Nguyen HT, Pessah IN, Allen PD. Dyspedic mouse skeletal muscle expresses major elements of the triadic junction but lacks detectable ryanodine receptor protein and function. J Biol Chem. 1997;272(11):7360-7.

18. Fan GC, Yuan Q, Zhao W, Chu G, Kranias EG. Junctin is a prominent regulator of contractility in cardiomyocytes. Biochem Biophys Res Commun. 2007;352(3):617-22.

19. Lahat H, Pras E, Olender T, Avidan N, Ben-Asher E, Man O, et al. A missense mutation in a highly conserved region of CASQ2 is associated with autosomal recessive catecholamine-induced polymorphic ventricular tachycardia in Bedouin families from Israel. Am J Hum Genet. 2001;69 (6):1378-84

20. Rezgui SS, Vassilopoulos S, Brocard J, Platel JC, Bouron A, Arnoult C, et al. Triadin (Trisk 95) overexpression blocks excitation-contraction coupling in rat skeletal myotubes. J Biol Chem. 2005;280(47):39302-8.

21. Roux-Buisson N, Cacheux M, Fourest-Lieuvin A, Fauconnier J, Brocard J, Denjoy I, et al. Absence of triadin, a protein of the calcium release complex, is responsible for cardiac arrhythmia with sudden death in human. Hum Mol Genet. 2012;21 (12):2759-67.

22. Terentyev D, Cala SE, Houle TD, Viatchenko-Karpinski S, Gyorke I, Terentyeva $\mathrm{R}$, et al. Triadin overexpression stimulates excitation-contraction coupling and increases predisposition to cellular arrhythmia in cardiac myocytes. Circ Res. 2005;96(6):651-8.

23. Venetucci L, Denegri M, Napolitano C, Priori SG. Inherited calcium channelopathies in the pathophysiology of arrhythmias. Nat Rev Cardiol. 2012;10:561-75.

24. Franzini-Armstrong C, Kenney LJ, Varriano-Marston E. The structure of calsequestrin in triads of vertebrate skeletal muscle: a deep-etch study. J Cell Biol. 1987;105(1):49-56.

25. Cozens B, Reithmeier RA. Size and shape of rabbit skeletal muscle calsequestrin. J Biol Chem. 1984;259(10):6248-52.

26. Ikemoto N, Bhatnagar GM, Nagy B, Gergely J. Interaction of divalent cations with the 55,000-dalton protein component of the sarcoplasmic reticulum. Studies of fluorescence and circular dichroism. J Biol Chem. 1972;247:7835-7.

27. Wang S, Trumble WR, Liao H, Wesson CR, Dunker AK, Kang CH. Crystal structure of calsequestrin from rabbit skeletal muscle sarcoplasmic reticulum. Nat Struct Biol. 1998;5:476-83.

28. Ostwald TJ, MacLennan DH, Dorrington KJ. Effects of cation binding on the conformation of calsequestrin and the high affinity calcium-binding protein of sarcoplasmic reticulum. J Biol Chem. 1974;249(18):5867-71.

29. Park H, Wu S, Dunker AK, Kang C. Polymerization of calsequestrin. Implications for $\mathrm{Ca}^{2+}$ regulation. J Biol Chem. 2003;278(18):16176-82.

30. Park H, Park IY, Kim E, Youn B, Fields K, Dunker AK, et al. Comparing skeletal and cardiac calsequestrin structures and their calcium binding: a proposed mechanism for coupled calcium binding and protein polymerization. J Biol Chem. 2004;279(17):18026-33. 
31. Nori A, Gola E, Tosato S, Cantini M, Volpe P. Targeting of calsequestrin to sarcoplasmic reticulum after deletions of its acidic carboxy terminus. Am J Physiol. 1999;277(5 Pt 1):C974-81.

32. Kumar A, Chakravarty H, Bal NC, Balaraju T, Jena N, Misra G, et al. Identification of calcium binding sites on calsequestrin 1 and their implications for polymerization. Mol Biosyst. 2013;9(7):1949-57.

33. Gaburjakova M, Bal NC, Gaburjakova J, Periasamy M. Functional interaction between calsequestrin and ryanodine receptor in the heart. Cell Mol Life Sci. 2013;70(16):2935-45.

34. Beard NA, Casarotto MG, Wei L, Varsanyi M, Laver DR, Dulhunty AF. Regulation of ryanodine receptors by calsequestrin: effect of high luminal $\mathrm{Ca}^{2+}$ and phosphorylation. Biophys J. 2005;88(5):3444-54.

35. Saito A, Seiler S, Chu A, Fleischer S. Preparation and morphology of sarcoplasmic reticulum terminal cisternae from rabbit skeletal muscle. J Cell Biol. 1984;99:875-85.

36. Lai FA, Erickson HP, Rousseau E, Liu QY, Meissner G. Purification and reconstitution of the calcium release channel from skeletal muscle. Nature. 1988:331:315-9.

37. Laemmli UK. Cleavage of structural proteins during the assembly of the head of bacteriophage T4. Nature. 1970;227:680-5.

38. Towbin $\mathrm{H}$, Staehelin T, Gordon J. Electrophoretic transfer of proteins from polyacrylamide gels to nitrocellulose sheets: procedure and some applications. Proc Natl Acad Sci U S A. 1979;76:4350-4.

39. Wei L, Gallant EM, Dulhunty AF, Beard NA. Junctin and triadin each activate skeletal ryanodine receptors but junctin alone mediates functional interactions with calsequestrin. Int J Biochem Cell Biol. 2009:41(11):2214-24.

40. Bal NC, Jena N, Chakravarty H, Kumar A, Chi M, Balaraju T, et al. The C-terminal calcium-sensitive disordered motifs regulate isoform-specific polymerization characteristics of calsequestrin. Biopolymers. 2014;103(1):15-22.

41. Valle G, Galla D, Nori A, Priori SG, Gyorke S, de Filippis V, et al, Catecholaminergic polymorphic ventricular tachycardia-related mutations R33Q and L167H alter calcium sensitivity of human cardiac calsequestrin. Biochem J. 2008;413(2):291-303.

42. Beard NA, Wei L, Cheung SN, Kimura T, Varsanyi M, Dulhunty AF Phosphorylation of skeletal muscle calsequestrin enhances its $\mathrm{Ca}^{2+}$ binding capacity and promotes its association with junctin. Cell Calcium. 2008;44 (4):363-73.

43. Herzog A, Szegedi C, Jona I, Herberg FW, Varsanyi M. Surface plasmon resonance studies prove the interaction of skeletal muscle sarcoplasmic reticular $\mathrm{Ca}^{2+}$ release channel/ryanodine receptor with calsequestrin. FEBS Lett. 2000:472:73-7.

44. Krause KH, Milos M, Luan Rilliet Y, Lew DP, Cox JA. Thermodynamics of cation binding to rabbit skeletal muscle calsequestrin. Evidence for distinct $\mathrm{Ca}^{2+}$ - and $\mathrm{Mg}^{2+}$-binding sites. J Biol Chem. 1991;266:9453-9.

45. Boncompagni S, Thomas M, Lopez JR, Allen PD, Yuan Q, Kranias EG, et al. Triadin/junctin double null mouse reveals a differential role for triadin and junctin in anchoring CASQ to the jSR and regulating $\mathrm{Ca}^{2+}$ homeostasis. PLoS One. 2012;7(7):e39962.

46. Wang Y, Li X, Duan H, Fulton TR, Eu JP, Meissner G. Altered stored calcium release in skeletal myotubes deficient of triadin and junctin. Cell Calcium. 2009;45(1):29-37.

47. Dainese M, Quarta M, Lyfenko AD, Paolini C, Canato M, Reggiani C, et al. Anesthetic- and heat-induced sudden death in calsequestrin-1-knockout mice. FASEB J. 2009;23(6):1710-20.

48. Protasi F, Paolini C, Canato M, Reggiani C, Quarta M. Lessons from calsequestrin-1 ablation in vivo: much more than a $\mathrm{Ca}^{2+}$ buffer after all. J Muscle Res Cell Motil. 2011:32(4-5):257-70.

\section{Submit your next manuscript to BioMed Central and take full advantage of:}

- Convenient online submission

- Thorough peer review

- No space constraints or color figure charges

- Immediate publication on acceptance

- Inclusion in PubMed, CAS, Scopus and Google Scholar

- Research which is freely available for redistribution 